\section{Sediment Reduction from the Use of Lowered Tire Pressures}

Randy B. Foltz

U.S. Forest Service, Intermountain Research Station

\section{ABSTRACT}

The use of lowered tire pressures has the capability to reduce sediment production from unpaved forest roads. A three year test of Central Tire Inflation System (CTIS) and Constant Reduced Pressure (CRP) methods to achieve lowered tire pressures was conducted by the U.S. Forest Service. The average sediment reduction from the use of CTIS was $80 \%$ compared to highway tire pressures. When using CRP tire pressures, the average sediment reduction was $45 \%$ compared to highway tire pressures. Both lowered tire pressure systems had shallower, less well defined wheel ruts resulting in less frequent road maintenance requirements.

\section{INTRODUCTION}

The U.S. Forest Service maintains 351,000 miles of unsurfaced or aggregate surfaced roads to access nearly 191 million acres of forest and grasslands. Roads are believed to be a major contributor to stream sedimentation resulting in loss of aquatic habitat and degraded water quality.

Heavy truck traffic has been identified as a major cause of sedimentation on unpaved forest roads (1). Roads that have been allowed to become rutted can produce from two to four times as much sediment as freshly-graded roads $(2,3)$.

A system to reduce the impact of surface erosion from unpaved forest roads would be one that reduced the tendency of heavy vehicles to form wheel ruts. One such system spreads the vehicle load over a larger area on the road surface. Two methods are available to accomplish this task, Central Tire Inflation System (CTIS) and Constant Reduced Pressure (CRP).

Central Tire Inflation Systems are an evolving technology that have been used by the U.S. Army since before World War II to improve vehicle mobility. The technology allows a vehicle driver to reduce tire pressure while in motion. The reduced tire pressure, when used with radial ply tires, results in a longer "footprint". This longer footprint reduces the vehicle pressures applied to the ground. The tire pressure is chosen depending upon vehicle weight, speed, tire type, and road surface. Modifications to the vehicle are required to install a CTIS. The system has been used on loaded and unloaded logging trucks, dump trucks, and other heavy weight vehicles.

With the Constant Reduced Pressure method, the driver manually lowers the tire pressure in each of the vehicle tires. The vehicle does not require any modifications. The minimum tire pressure depends on gross weight, maximum speed, and tire type. The tire pressure cannot be changed without stopping the vehicle. Tire pressures and, therefore, ground contact pressures with CRP are generally not as low as with CTIS.

In 1990 the USDA Forest Service Intermountain Research Station conducted a test of CTIS to reduce sedimentation from a native surfaced forest road. Rainfall simulation on two $30.5 \mathrm{~m}$ long test sections indicated a $38 \%$ sediment reduction was achieved by reducing tire pressure from highway pressure to CTIS pressures (3).

In January 1992 a three-year study was begun on the Lowell Ranger District of the Willamette National Forest in Oregon to investigate aggregate quality impacts on sedimentation and tire pressure impacts on sedimentation. The aggregate quality impacts will be presented in (4). The comparison of the tire pressure systems is reported in this paper.

\section{COLLECTION OF DATA}

TEST SITE-A $2.25 \mathrm{~km}$ long by $4.27 \mathrm{~m}$ wide, crowned section of forest road on the Lowell District of the Willamette National Forest, Oregon was selected for the test. This road was chosen to meet the requirements of length, constant grade, and the ability to control non-test traffic. Three 61 meter long sections with similar grade of $12 \%$ were selected. Each section was surfaced with $100 \mathrm{~mm}$ of $76 \mathrm{~mm}$ aggregate on top of the existing 300-400 mm thickness of $76 \mathrm{~mm}$ minus subgrade.

Aggregate Specifications-The aggregate placed on the road passed the Forest Service size gradation specifications, but was not within specifications for Durability Index of the fine fraction and the Sand Equivalent test. The Durability Index of the fines averaged 31 indicating an aggregate susceptible to breakdown by traffic. The minimum recommended value was 35 . The Sand Equivalent value averaged 22, well below the minimum value of 35. Sand Equivalent is an empirical test of the amount of material remaining in suspension after agitation. This aggregate was considered to be typical of 
lower quality aggregate often used by forests in lieu of higher quality, more expensive aggregate.

Runoff Measurements-Two runoff measurement collectors were located on each test section. One collected a portion of the runoff flowing laterally off both sides of the road crown, while a second collected runoff flowing longitudinally down the road in the wheel ruts. Continuous measurements of flow were made. Sediment trapped in a $0.15 \mathrm{~m}^{3}$ settling box was collected approximately every three weeks.

The material collected in the settling boxes represented only a portion of the material eroded from the road surface. Sand and larger sizes were trapped with efficiencies increasing with size. Alternatively, the silt and clay sizes did not have sufficient resident time to completely settle. Generally the settling boxes on the sides of the road crown received overland flow at low rates, while the boxes that collected runoff flowing down the wheel ruts received higher concentrated flows. These differences were reflected in the average trap efficiencies determined for the two locations of the settling boxes. When expressed as a percent of material remaining in the settling box, the average trap efficiency for the boxes located on the sides of the road were $40.2 \%$ and $35.6 \%$ in the boxes receiving flow from the wheel ruts. All reported sediment values contain these trap efficiency adjustments.

An estimate of the runoff and sediment production from the entire road section was made from the two collectors. Since the lateral collectors extended for $1 / 4$ of the length of the entire road section, it was assumed that they collected $1 / 4$ of the total runoff flowing off the crown of the road. Observations of the flow tended to validate this assumption. The runoff rates from the lateral collector was multiplied by four and added to the longitudinal collector for an estimate of the entire road section.

TIRE PRESSURES-Each of the three test sections was dedicated to a single tire pressure system (see Table 1). One test section received only CTIS pressures. One test section received only CRP pressures, and the third test section received only highway pressures. Pressure changes were made between test sections. CTIS pressures were chosen based on the particular load and speed of the trucks. The CRP pressures were chosen based on the load and the criteria to run on paved roads at $55 \mathrm{mph}$ indefinitely. The highway pressures were representative of typical truck operations. All pressures were consistent with the Tire and Rim Association (5) recommendations.

TRUCK TRAFFIC-To simulate the effects of road use from a timber harvest, loaded and unloaded trucks were driven on the test loop. Prior to each season's truck traffic, the sections were graded to remove wheel ruts. The first season of the test, two trucks were used. One western style logging truck carrying $22,450 \mathrm{~kg}$ of $\operatorname{logs}$ was driven downhill. A dump truck with the same axle spacing as an unloaded logging truck carrying its trailer was driven up the hill. During the second and third season, a second loaded logging truck was added. It also carried $22,450 \mathrm{~kg}$ of $\operatorname{logs}$ and was driven downhill. The dump truck made twice as many passes as one of the logging trucks to maintain the desired ratio of one loaded truck for each unloaded truck. Driving was done on eight consecutive days of each two week period, including during rainfall events. No driving on frozen conditions was permitted. All vehicles were equipped with CTIS to facilitate pressure changes. This paper will use the term "load" to mean the combination of one loaded logging truck passing a road section and one unloaded logging truck passing in the opposite direction over the road section.

TEST DURATIONS-Each season the test portion lasted for approximately 3 months from mid-January through March. The test was conducted in 1992, 1993, and 1994.

RAINFALL SIMULATION-At the conclusion of the 1993 test period, rainfall simulation was performed. The simulator used had nineteen Rainjet 78C sprinkler heads located on 3 meter tall risers (CSU-type). A single storm with an intensity of $50 \mathrm{~mm} / \mathrm{hr}$ and a duration of 30 minutes was applied to each road test section. Each section was left in the condition following traffic, but was shortened to 42.7 $\mathrm{m}$ to not exceed the capacity of the flow measuring devices. Runoff measurements were taken at one-minutes intervals and sediment samples at 70 -second intervals. An estimate of the runoff and erosion from the entire road section was made in the same manner as for the natural rainfall, but adjusted for the shorter test section length.

\section{RESULTS AND DISCUSSION}

The precipitation and truck traffic for each year are summarized in Table 2. A wide range of precipitation from 147 to $521 \mathrm{~mm}$ fell during the test period. In 1993, the precipitation of $521 \mathrm{~mm}$ includes $249 \mathrm{~mm}$ of snow that fell between January 7 and 22.

SEDIMENT PRODUCTION-Table 3 shows the sediment production from each tire pressure system. This mass represented the amount of material eroded from the road surfaces. Virtually all of the eroded material, $96 \%$ to $99 \%$, was less than $6 \mathrm{~mm}$ size. Silts and clays typically comprised 65 percent by weight of the runoff. 


\begin{tabular}{lllll}
\hline & \multicolumn{2}{l}{ Unloaded Truck } & \multicolumn{2}{l}{ Loaded Truck } \\
\cline { 2 - 5 } $\begin{array}{l}\text { Tire } \\
\text { Pressure } \\
\text { System }\end{array}$ & $\begin{array}{l}\text { Steering } \\
\text { Axle } \\
(\mathrm{kPa})\end{array}$ & $\begin{array}{l}\text { Other } \\
\text { Axles } \\
(\mathrm{kPa})\end{array}$ & $\begin{array}{l}\text { Steering } \\
\text { Axle } \\
(\mathrm{kPa})\end{array}$ & $\begin{array}{l}\text { Other } \\
\text { Axles } \\
(\mathrm{kPa})\end{array}$ \\
\hline CTIS & 480 & 210 & 480 & 340 \\
CRP & 480 & 480 & 480 & 480 \\
Highway & 620 & 620 & 620 & 620 \\
\hline $\begin{array}{l}\text { CTIS-Central Tire Inflation System } \\
\text { CRP-Constant Reduced Pressure }\end{array}$ \\
Highway-Highway Tire Pressure
\end{tabular}

The values for sediment production and sediment yield reported in Table 3 were specific for the Lowell test site. In order to generalize these results, the percent reduction of sediment from the CTIS test section compared to the highway pressure test section and the percent reduction of sediment from the CRP test section to the highway pressure test section were determined, and are presented in Table 4. These values represent the sediment benefit achieved from the use of the particular reduced tire pressure system. While the sediment yields from various geological parent materials may be different, the percent reduction would be expected to remain similar.

The observed values for the percent reduction when combining the three test periods for the CTIS section was $80 \%$. The values ranged from $87 \%$ to $70 \%$ on a yearly basis. The greatest improvement, $87 \%$, occurred in the year with the greatest rainfall.

The percent reduction when the three test periods were combined for the CRP pressure section was $45 \%$, and ranged from $15 \%$ to $59 \%$. The least improvement, $15 \%$, occurred in the year with the least rainfall.

RUT DEPTHS-Figure 1 presents the pre-traffic and post-traffic cross-section for the 1994 test period. The amount of truck traffic and the precipitation on each testsection were the same. Reduced tire pressures showed a marked difference in the development of rutting. Using a peak-to-peak measure of the depth of a rut, the highway tire pressure section resulted in a $133 \mathrm{~mm}$ deep rut compared to a $8 \mathrm{~mm}$ deep rut on the CTIS section and a $32 \mathrm{~mm}$ deep rut on the CRP section. This degree of rutting was largely responsible for the differences in sediment production observed on each test section.

The mechanism by which the sediment reduction occurs is the prevention of surface rutting and resulting concentrated flow. Since ruts and the detrimental effect of concentrated flow are not site specific, the benefits of reduced tire pressure are not site specific either. Tests conducted by the Intermountain Research Station over a wide range of geologic parent materials have shown that ruts produce 2 to 4 times as much sediment as unrutted road surfaces (6). As the Lowell test demonstrates, the degree of rutting was proportional to the sediment production.

Table 2: Precipitation and Traffic Summary.

\begin{tabular}{ccccc}
\hline & & \multicolumn{2}{c}{ Maximum Precipitation } & \\
\cline { 3 - 4 } Year & $\begin{array}{c}\text { Precip } \\
(\mathrm{mm})\end{array}$ & $\begin{array}{c}\text { Daily } \\
(\mathrm{mm})\end{array}$ & $\begin{array}{c}\text { 5-min. Intensity } \\
(\mathrm{mm})\end{array}$ & $\begin{array}{c}\text { Traffic } \\
\text { (loads) }\end{array}$ \\
\hline 1992 & 147 & 31 & 18 & 268 \\
1993 & 521 & 44 & 17 & 616 \\
1994 & 336 & 30 & 24 & 1205 \\
\hline
\end{tabular}

Table 3: Sediment Production, Natural Rainfall Events.

\begin{tabular}{lcccc}
\hline \multicolumn{5}{c}{ Mass Sediment $(\mathrm{kg})$} \\
Tire \\
Pressure & 1992 & 1993 & 1994 & Total \\
\hline CTIS & 13.98 & 176.21 & 339.94 & 530.13 \\
CRP & 40.09 & 918.37 & 507.01 & 1465.47 \\
Highway & 47.27 & 1399.70 & 1231.33 & 2678.30 \\
\hline CTIS-Central Tire Inflation System \\
CRP-Constant Reduced Pressure \\
Highway-Highway Tire Pressure \\
\hline
\end{tabular}

RUT DEVELOPMENT-Figure 2 shows the depth of the ruts with truck traffic during the 1993 test period. The CTIS section showed little change of depth with traffic, i.e. the ruts did not deepen. The CRP section deepened only slightly with traffic. This is in contrast to the highway section that deepened from an initial $38 \mathrm{~mm}$ to $127 \mathrm{~mm}$. This graph shows that the reduced tire pressures, and especially the CTIS pressures, did less damage to the aggregate surfaced road.

Also noteworthy in Figure 2 was the concave downward shape of the depth vs. traffic curve. Half of the increase in rut depth occurred after only $15 \%$ of the total truck traffic. This behavior is predicted by the Surface Thickness Prediction (STP) equation used by the US Forest Service to predict rut depths (7). While this non-linear rut depth development is common, the STP equation is 
recommended rather than attempting to extrapolate the Lowell results.

Table 4: Sediment Reduction, Natural Rainfall Events.

\begin{tabular}{|c|c|c|c|c|}
\hline \multirow{2}{*}{$\begin{array}{l}\text { Tire } \\
\text { Pressure }\end{array}$} & \multicolumn{4}{|c|}{ Sediment Reduction (\%) } \\
\hline & 1992 & 1993 & 1994 & Average \\
\hline CTIS & 70 & 87 & 72 & 80 \\
\hline CRP & 15 & 34 & 59 & 45 \\
\hline \multicolumn{5}{|c|}{$\frac{\text { Sediment }_{\text {highway }}-\text { Sediment }_{1}}{\text { Sediment }} * 100$} \\
\hline \multicolumn{5}{|c|}{$\begin{array}{l}\text { CTIS-Central Tire Inflation System } \\
\text { CRP-Constant Reduced Pressure } \\
\text { Highway-Highway Tire Pressure }\end{array}$} \\
\hline
\end{tabular}

SIMULATED STORM-Table 5 gives the peak flow rates from the rainfall simulations. Overland flow (lateral flow collector) predominated on the CTIS and the CRP sections, but concentrated flow (longitudinal flow collector) predominated on the highway pressure section.

Table 6 presents the sediment production results from the simulated storms. As was observed from the natural events and expected from the type of flow occurring on the road sections, the greatest sediment production occurred on the highway section. The percent reductions of $83 \%$ and $47 \%$ for the CTIS and CRP sections were comparable to the average percent reductions for the entire test period (see Table 3). In locations where summer thunderstorms are the predominate erosion causing mechanism, this simulated storm may provide a better estimate of the effect of reduced tire pressures than the Oregon winter observations.

The simulated storm did not have traffic during the event, so could not measure the immediate effect of the trucks during the event. Neither were the long term effects of truck traffic, such as breakdown of the aggregate, possible during the simulation. While the long term effects of truck traffic were not measured, the simulation represents the effects of a single storm without traffic.

\section{MANAGEMENT IMPLICATIONS}

The results of the three year study had several management implications for forest road management. One was that tire pressure in logging trucks had an impact on sediment production. Simply reducing the tire pressure from $620 \mathrm{kPa}$ to $480 \mathrm{kPa}$ resulted in a $45 \%$ reduction in sediment loss. This level of sediment mitigation could be achieved without modifications to existing vehicles. In situations where the logging trucks would not travel on paved roads, tire pressures could be reduced below the 480 $\mathrm{kPa}$ consistent with Tire and Rim Association's recommendations. Such situations include areas where there are no paved roads, log transfer stations at the end of the unpaved roads, or airing stations at the end of the unpaved road sections.

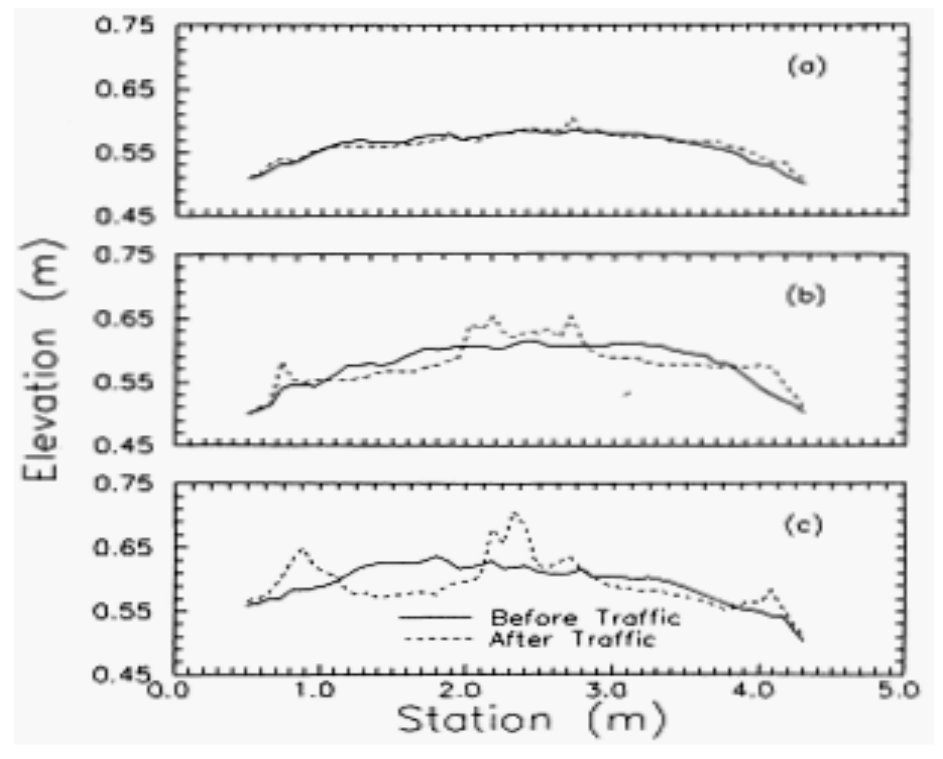

Figure 1- Road cross-sections from sections with (a) CTIS tire pressures, (b) CRP tire pressures, and (c) highway tire pressures for 1994 test season. "Before traffic" was after grading and before logging truck traffic. "After traffic" was after 6.0 million board feet haul (1205 loads).

The use of Central Tire Inflation System vehicles reduced sediment production by $80 \%$. Although the cost of equipping vehicles with CTIS is not trivial $(\$ 10,000$ to $\$ 15,000$ per truck), the ability to reduce sediment production from the road surface by $80 \%$ could mean the difference in operating in sensitive areas and not operating. When combined with the demonstrated ability of CTIS equipped trucks to operate on steep adverse grades without assistance and reduced vehicle maintenance costs (8), CTIS equipped logging trucks could be cost effective in certain logging conditions. Not all road generated sediment comes from the traveled way so cost effectiveness will vary depending upon the relative sediment contribution of each portion of the road prism. 


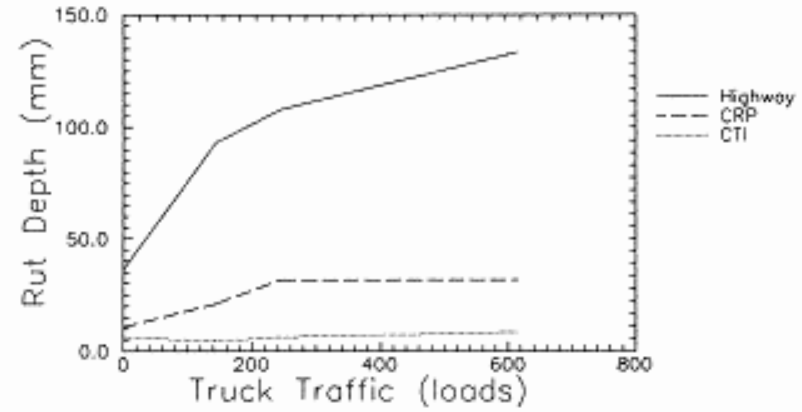

Figure 2-Rut depth development with logging truck traffic for 1993 test season.

A second benefit of reduced tire pressures was less frequent road maintenance. As shown by Figure 1, both reduced tire pressure systems resulted in shallower, less well defined wheel ruts, causing less frequent road blading to remove the ruts. This reduced maintenance frequency is an additional cost advantage to both reduced tire pressure regimes. During each year of test, the highway tire pressure section would have been bladed under normal operational conditions, but not the reduced tire pressure section.

Table 5: Peak Runoff Rates from Simulated Storm.

\begin{tabular}{lrc}
\hline Tire Pressure & $\begin{array}{c}\text { Lateral Flow } \\
\text { Collector } \\
(\mathrm{ml} / \mathrm{sec})\end{array}$ & $\begin{array}{c}\text { Longitudinal Flow } \\
\text { Collector } \\
(\mathrm{ml} / \mathrm{sec})\end{array}$ \\
\hline CTIS & 975 & 477 \\
CRP & 1196 & 570 \\
Highway & 508 & 1675 \\
\hline CTIS-Central Tire Inflation System & \\
CRP-Constant Reduced Pressure & \\
Highway-Highway Tire Pressure & \\
\hline
\end{tabular}

As previously discussed, these tests were performed on marginal quality aggregate that did not meet durability and sand equivalent specifications. This marginal quality aggregate had an impact on the sediment production and the percent reduction. Had the aggregate been less susceptible to mechanical breakdown, the benefit from using reduced tire pressures would not have been as great. With the range in particle sizes from gravel to fine silts, the flow would have winnowed away the small moveable sizes leaving behind the larger non-moveable ones. After a sufficient flow, the larger sizes would have covered and hidden the smaller ones from transport by the flow. This condition occurs in rivers and is known as armoring. The aggregate used in the test did not have sufficient resistance to mechanical breakdown and continued to generate additional fines preventing significant armoring from occurring. A more durable aggregate would be less susceptible to mechanical breakdown and continued replacement of transportable fines.

SEDIMENT MITIGATION-The simulated storm makes possible an estimation of the mitigation provided by the aggregate with the addition of traffic. The subgrade at the test site was similar to a coarse silt site in Central Idaho reported by Foltz (6). A road section with a length of 38.1 $\mathrm{m}$ and a nearly saturated water content had a sediment production of $9200 \mathrm{~kg} / \mathrm{ha}$ using the same CSU-type simulator. With this as a base case, the CTIS section had a $79 \%$ mitigation of sediment, the CRP section had a $70 \%$ mitigation of sediment, and the highway pressure section had a $36 \%$ mitigation of sediment.

Table 6: Sediment Mass and Sediment Reduction from Simulated Storm.

\begin{tabular}{|c|c|c|}
\hline Tire Pressure & $\begin{array}{c}\text { Mass Sediment } \\
(\mathrm{kg})\end{array}$ & $\begin{array}{l}\text { Sediment } \\
\text { Reduction (\%) }\end{array}$ \\
\hline CTIS & 38.1 & 83 \\
\hline CRP & 54.2 & 47 \\
\hline Highway & 116.0 & 0 \\
\hline \multicolumn{3}{|c|}{ Sediment $t_{\text {hlqhway }}-$ Sediment $t_{1} * 100$} \\
\hline $\begin{array}{l}\text { CTIS-Central } \\
\text { CRP-Constant } \\
\text { Highway-High }\end{array}$ & $\begin{array}{l}\text { llation System } \\
\text { ed Pressure } \\
\text { ire Pressure }\end{array}$ & \\
\hline
\end{tabular}

Burroughs and King (9) estimated a sediment reduction of $95 \%$ for the test site conditions, if the aggregate was high quality and there was no traffic. The Lowell test demonstrated that the addition of traffic, regardless of tire pressures used, on marginal durability aggregate reduced the effectiveness of the aggregate as a sediment mitigation measure.

Even with the addition of CTIS equipped vehicles, the full mitigation potential of high quality aggregate was not realized. However as discussed in (4), the full potential was achieved with high quality aggregate and highway tire pressure truck traffic and rainfall.

\section{SUMMARY AND CONCLUSIONS}

A three year test of the effect of tire pressure on sediment production demonstrated that reduced tire 
pressures in heavy vehicles reduced the amount of sediment produced from the road surface. A simulated log haul using Central Tire Inflation System equipped logging trucks produced 0.20 units of sediment for every 1 unit of sediment produced from a road section with highway tire pressures ( $80 \%$ sediment reduction). A simulated log haul using logging trucks operating with reduced tire pressures, but not as low as the CTIS trucks, caused 0.55 units of sediment for every 1 unit of sediment from a road section with highway tire pressures ( $45 \%$ sediment reduction). While the economics of which reduced tire pressure system would be most cost effective depend upon site specific conditions, the use of reduced tire pressure lessens the amount of sediment produced from unpaved forest roads.

The mechanism by which the reduction in sediment production occurs is the prevention of surface rutting and concentrated flow. Since ruts and the benefits of avoiding concentrated flow are not site specific, the existence of the benefits of reduced tire pressure are not site specific, only the magnitude of those benefits.

Reduced tire pressure also results in less frequent road maintenance to remove wheel ruts. For forests with limited maintenance budgets, this benefit would add to the cost effectiveness of reduced tire pressure vehicles.

Estimates of sediment mitigation based on the use of high quality aggregate were not achieved using marginal durability aggregate quality and heavy vehicle traffic. Careful attention to aggregate and vehicular traffic should be exercised when determining mitigation values.

\section{ACKNOWLEDGEMENTS}

The author would like to acknowledge the financial and technical support and the loan of a logging truck from the USDA Forest Service San Dimas Technology and Development Center. The assistance of the Willamette National Forest notably Larry Tennis of the Lowell Ranger District and Mark Truebe and Gary Evans of the supervisor's office was appreciated. A special acknowledgement to Ben Kopyscianski of the Intermountain Research Station who lead the individuals who collected samples and maintained equipment in the cold and rain of three Oregon winters.

\section{REFERENCES}

1. R.E. Bilby, K. Sullivan, and S.H. Duncan. 1989. The Generation and Fate of Road-surface sediment in Forested Watersheds in Southeastern Washington. Forest Science, v35, n2, pp 453-468.
2. R.B. Foltz and E.R. Burroughs, Jr. 1990. Sediment Production from Forest Roads with Wheel Ruts. Proceedings from Watershed Planning and Analysis in Action, American Society of Civil Engineers, Durango, CO.

3. R.B. Foltz and E.R. Burroughs, Jr. 1991. A Test of Normal Tire Pressure and Reduced Tire Pressure on Forest Roads: Sedimentation Effects. Proceedings from Forestry and Environment...Engineering Solutions, Forest Engineering Group, American Society of Agricultural Engineers, New Orleans, LA.

4. R.B. Foltz and M.A. Truebe. in press. The Effect of Aggregate Quality on Sediment Production From a Forest Road.Proceedings from Low Volume Roads Conference, Washington, DC.

5. The Tire and Rim Association, Inc. 1991. Design Guide-Reduced Inflation Pressure Limits for Radial Ply Tubeless Truck Tires Used Off Highway at Reduced Speed. 175 Montrose West Ave, Suite 150, Copley, OH.

6. R.B. Foltz. 1993. Sediment Processes in Wheel Ruts on Unsurfaced Forest Roads. PhD Dissertation, University of Idaho, Moscow, ID.

7. W.G. Witcomb, M.T. Yapp, and M. Myers. 1990. Aggregate Surfacing Design Guide. Final Report, Contract 53-04H1-8-6230, USDA Forest Service, Portland, OR.

8. R.R. Keller. 1992. The Results of Operational Testing of Central Tire Inflation Systems Proves the Benefits of Low Tire Pressure in Logging Operations. Proceedings of Planning and Implementing Future Forest Operations. College of Natural Resources, University of Washington, Seattle, WA.

9. E.R. Burroughs, Jr. and J.G. King. 1989. Reduction of Soil Erosion on Forest Roads. General Technical Report INT-264, Intermountain Research Station, USDA Forest Service.

The use of trade or firm names in this paper is for reader information and does not imply endorsement by the U.S. Department of Agriculture of any product or service.

Published as:

Foltz, R.B. 1995. Sediment Reduction from the Use of Lowered Tire Pressures. In: Central tire inflation systems: managing the vehicle to surface. SP-1061.Warrendale, PA: Society of Automotive Engineers: 47-52; SAE Technical Paper Series, 942244. 